\title{
Comment on: 'Ophthalmology Specialist Trainee Survey in the United Kingdom'. The need to increase familiarity with the management of predictable cataract surgery complications via simulation-ensuring competence to improve confidence
}

\author{
Jonathan Nairn ${ }^{1} \cdot$ Larry Benjamin $^{2} \cdot$ David Lockington $^{1}{ }^{1}$ \\ Received: 25 June 2019 / Accepted: 17 October 2019 / Published online: 21 November 2019 \\ (c) The Royal College of Ophthalmologists 2019
}

\section{To the Editor:}

We read with interest the recently published findings within "Ophthalmology specialist trainee survey in the United Kingdom" [1]. By year 4 and beyond, all respondents reported $100 \%$ confidence in performing cataract surgery independently, yet paradoxically this was not matched by the confidence to perform anterior vitrectomy (the technique required to safely address the most commonly associated complication of phacoemulsification). We would therefore suggest that, by definition, such surgeons are not competent to perform independent surgery without that skill set.

Specifically, "one out of eleven final-year trainees did not feel confident in independently performing an anterior vitrectomy."[1] In other words, 9\% of these soon-to-be consultants may not be capable to effectively address posterior capsule rupture/vitreous loss (PCR/VL), predicted to occur approximately every 50 cases $(1.92 \%)$ [2]. Does this reported lack of confidence reflect the true level of competence of the trainee, or alternatively, is it derived from a lack of familiarity with the required techniques?

A recent survey of all Scottish ophthalmic trainees regarding three-piece IOL use identified a massive gap in their surgical experience with sulcus IOL placement, either through training, observation or personal use [3]. As we now live in an era of pre-loaded injectable lenses, all members of the theatre staff are becoming deskilled and

David Lockington

davidlockington@hotmail.com

1 Tennent Institute of Ophthalmology, Gartnavel General Hospital, 1053 Great Western Road, Glasgow, Scotland G12 0YN, UK

2 Department of Ophthalmology, Stoke Mandeville Hospital, Aylesbury HP21 8AL, UK unfamiliar with the equipment required for three-piece IOLs, and this will compound a lack of confidence in the emergency setting of managing PCR/VL. How can the surgeon safely place an appropriate IOL in the sulcus without prior knowledge or training?

Simulation training has been shown to reduce intraoperative complication rates [4]. We have previously documented the importance of running regular simulation "fire drills" to practice the management of vitreous loss [5]. We suggest that running a regular three-piece IOL dry lab session would ensure competence in this infrequent but essential skill. The safe management of specific cataract surgery complications, even in dry lab simulation settings, should be mandatory competencies to be achieved prior to independent surgical practice, rather than 350 arbitrary cataract operations. Ensuring familiarity and competence with these vital techniques should consequently improve confidence in the management of cataract surgery related complications (for both surgeon and patient).

\section{Compliance with ethical standards}

Consent for publication Granted.

Conflict of interest The authors declare that they have no conflict of interest.

Publisher's note Springer Nature remains neutral with regard to jurisdictional claims in published maps and institutional affiliations.

\section{References}

1. Dean WH, Grant S, McHugh J, Bowes O, Spencer F. Ophthalmology specialist trainee survey in the United Kingdom. Eye. 2019;33:917-24. https://doi.org/10.1038/s41433-019-0344-z. 
2. Narendran N, Jaycock P, Johnston RL, et al. The cataract national dataset electronic multicentre audit of 55,567 operations: risk stratification for posterior capsule rupture and vitreous loss. Eye. 2009;23:31-7.

3. Guthrie S, Goudie C, Lockington D. Survey of Scottish ophthalmic trainees' experiences using 3-piece IOLs in cataract surgery. J Cataract Refract Surg. 2018;44:409. https://doi.org/10. 1016/j.jcrs.2018.01.016.
4. Ferris JD, Donachie PH, Johnston RL, Barnes B, Olaitan M, Sparrow JM. Royal College of Ophthalmologists' National Ophthalmology Database study of cataract surgery: report 6 . The impact of EyeSi virtual reality training on complications rates of cataract surgery performed by first and second year trainees. Br J Ophthalmol. 2019. https://doi.org/10.1136/bjophthalmol-2018-313817.

5. Lockington D, Belin $\mathrm{M}$, McGhee CNJ. The need for all cataract surgeons to run a regular vitreous loss fire drill. Eye. 2017;31:1120-1. 